\title{
Is there a gender difference in associates of adolescents' lifetime illicit drug use in Tehran, Iran?
}

Katayoon Khooshabi ${ }^{1}$, Setareh-Ameneh-Forouzan ${ }^{1}$, Akhgar Ghassabian², Shervin Assari ${ }^{2}$

${ }^{1}$ Iranian Research Centre for Substance Abuse and Dependence (IRCSAD), University of Social Welfare and Rehabilitation Science, Tehran, Iran

2Department for Drug Abuse Research, Medicine and Health Promotion Institute, Tehran, Iran

Submitted: 12 February 2009

Accepted: 4 May 2009

Arch Med Sci 2010; 6, 3: 399-406

DOI: 10.5114/aoms.2010.14263

Copyright $\odot 2010$ Termedia \& Banach

\begin{abstract}
Introduction: Information regarding gender differences in drug use of adolescents is essential for designing gender-specific drug prevention policies. This study was conducted in high school students in Tehran, Iran, in 2007. Here, we report the gender differences in lifetime prevalence as well as psychosocial associates of drug use.

Material and methods: This was a gender analysis of the data collected in a drug use survey conducted in a random sample of high school adolescents (573 boys and 551 girls) in Tehran, Iran, 2007. Demographic characteristics, parental and peers' substance use, school performance, religious beliefs, attachment, selfesteem and emotional intelligence (EI) were entered in logistic regression analyses to predict the lifetime illicit drug use in boy and girls, separately.

Results: Boys were more likely to report lifetime illicit drug use than girls $(10.1 \%$ vs. $6.4 \%, p=0.023$ ). Differences in the risk profile associated with lifetime illicit drug use by gender included history of substance use in the family, higher score of attachment, and having an employed mother as predictors of substance use in boys, but not girls.

Conclusions: Understanding this gender difference in predictors of lifetime use of illicit drugs in high school adolescents facilitates the design of gender-sensitive drug use preventive programmes. It seems that family variables may have more value in prevention of illicit drug use in male adolescents.
\end{abstract}

Key words: adolescents, substance use, predictors, gender.

\section{Introduction}

The negative impact of substance use on physical and mental health $[1,2]$ parallel with its widespread consequences in the period of adolescence [3] leads researchers to widely investigate substance use and its prevalence and predictors in this age group [4].

A review of the literature in evidence derived from developed countries mostly points to having a disrupted family, a history of substance use by their parents as well as peers [2-4], the mutual parent-child relationship and their attachments [2], and emotional intelligence (EI) as important predictors of substance use and dependency [5].

Gender has been shown to be associated with substance use in adolescents $[2,6,7]$. While some studies have shown a predictive effect of gender on substance use in adolescents [2, 8], some other studies have
Corresponding author: Katayoon Khooshabi Koodakyar Str., Daneshjoo Blvd. Evin, Tehran, Iran Post code: $1985-713834$ Phone: 0098-21-221 80043 Fax: 0098-21-221 80043 E-mail: cru_common@yahoo.com 
shown that this difference is not always present in different cultures and societies [9]. Studies have shown that drug use has different risk factors in different genders $[10,11]$. Nevertheless, further research is needed to demonstrate that different predictors of substance use in male and female adolescents separately are always present.

There are very few published studies on epidemiology of drug abuse in adolescents in Iran. According to one study conducted in both genders in Tehran in 2000, about $15 \%$ reported usage of illicit drugs ever in their lives: opium (3.5\%), marijuana (3.8\%), heroin (2\%), LSD (0.5\%), cocaine $(1 \%)$, and morphine (0.8\%). Substance use was significantly higher among males than females and seeking pleasure and release of tension were the most common reasons for substance use [12]. Another study in Tabriz, Iran, in male adolescents reported a lifetime prevalence of $2.0 \%$. Studies have listed older age, having general risk-taking behaviour, higher smoking stage, having a history of self-injury and higher socioeconomic class as factors associated with student's ever use of illicit drugs $[13,14]$. In Iranian male adolescents, the major predictive factor for drug use was the extent of the individual's exposure to drug use by someone else as a model. Such models are more likely to be adult family members than the adolescent's age peers, opposite to the situation which is usually found in Europe and America [15]. In both adolescents and adults, drugs are the most important agents of acute poisoning in this country (69\%), especially sedative-hypnotics followed by opiates (12\%). Drugs were at the top of the list of causes of poisoning-related death in this country [16]. Opiates and other illicit drugs are among the causes of poisonings in Iran, in both genders [17].

Herein, we report the gender differences in predictive factors of lifetime illicit drug use in high school adolescents in Tehran, Iran, 2007.

\section{Material and methods}

\section{Subjects and methods}

This is a secondary analysis of a lifetime drug use survey in school-attending adolescents selected from 20 public high schools in Tehran, the capital of Iran, from January to March 2007. Participants were defined as adolescents on the basis of their age: from 11 to 18 years old. The study was approved ethically by the ethics committee of the Research Centre for Substance Abuse and Dependence (Darius Institute) and the Ministry of Education of the Islamic Republic of Iran. Verbal consent was obtained from respondents and they were reassured that their answers would be confidential.

\section{Samples and sampling}

For this survey, sampling was done using a cluster random sampling strategy. As 19 city zones exist in Tehran, we sampled 3 schools from each city zone to have a total of 57 schools from all parts of the city. We used the list of all public high schools in the city which was obtained from Tehran Education Organization for this sampling. In the next step of sampling, using computer-generated random numbers, we invited 21 randomly selected participants from each school (600 males and 600 females were invited in total). In Iran, girls and boys go to separate schools; therefore, 28 schools for boys and 29 schools for girls were selected. Sample size was calculated using the following formula for determining proportions: $n=N z 2 P(1-P) /[(N-1) d 2$ $+z 2 P(1-P)]$, considering $N=457056$ (obtained from Tehran Education Organization), $z=1.96$, $p=0.5$, and $d=0.05$. The value $n=384$ was multiplied by 3 (number of grades) and we came to the total sample of 1152 for both genders in all grades.

From this total, 1124 students participated in the study (97.60\%). This number included 573 boys (51.0\%) and 551 girls (49.0\%).

\section{Process}

The interviews were done by trained interviewers in school, in the class and privately without the presence of school directors and teachers. Each interview was carried out by one of two (one male and one female) research assistants, who had a background in research and data collection in the field of drug use and had perused the study protocol and undergone a training session regarding the study questionnaires. Each interview took about $1: 30-2 \mathrm{~h}$ for each subject. Participants were highly cooperative, although a large number of questions were asked via interview.

\section{Measures}

\section{Predictors}

An anonymous checklist was used to gather variables on demographic characteristics of adolescents such as work of mother and father, being a single child of the family (without any siblings), having an intact family (with both parents present in the family), as well as substance related variables such as family history of cigarette and substance use, peers' history of cigarette and substance use and seeing someone using substances (dichotomous answers: yes/no). Their school performance was scored via 3 questions on their total average grade during the previous year (less than $10=1,11$ to $12=2,13$ to $15=3,16$ to 
$18=4$, and 19 to $20=5$ ), their self-reported school performance (excellent $=4$, good $=3$, moderate $=2$ and poor $=1$ ) and what they believed about their school performance (to be excellent $=4$, good $=3$, moderate $=2$ and poor $=1$ ). For their religious beliefs, 5 questions on self-reported religious beliefs (strongly $=4$, moderately $=3$, a little $=2$, and not at all =1), how important this belief is in their life (a lot $=4$, to some extent $=3$, a little $=2$, and never $=1$ ), religious practice (a lot $=4$, to some extent $=3$, a little $=2$, and never $=1$ ) and how often their religious beliefs help them (a lot $=4$, to some extent $=3$, a little $=2$, and never $=1$ ) and if they encourage others to have religious beliefs (a lot $=4$, to some extent $=3$, a little $=2$, and never $=1$ ). Higher score for school performance and religious beliefs meant a better performance in school and being more religious.

The following questionnaires were used to assess attachment, self-esteem and emotional intelligence of the participants:

1. Modified version of Collins and Reed Inventory on attachment [18] for Iranian society with 75 items to calculate the total and scaled attachment score of adolescents. This inventory was in three parts (attachment to father, mother and peers), each of them consisting of 25 questions. Each question was measured on a 5-point Likert scale (almost always $=5$, usually $=4$, often $=3$, rarely $=2$, almost never $=1$ ). The abovementioned inventory was validated by Pakdaman et al. by performing a test-retest study with onemonth interval and the correlation coefficient was reported to be 0.75 [19]. Cronbach's coefficient alpha for the above-mentioned attachment scale was 0.72 in this study.

2. Coopersmith Self-esteem Inventory for adolescents, with 58 items (with yes/no answer for each question) to calculate the total selfesteem score by defining their attitude towards themselves in social, academic, familial and social areas of life. A high score in this questionnaire means high self-esteem [20]. The Farsi version of this simple, easy to answer and understandable questionnaire, with an acceptable reliability and validity in the Iranian population, was used [21, 22]. Cronbach's coefficient $\alpha$ of this Farsi version of the mentioned questionnaire was 0.82 in this study.

3. Bar-On Emotional Quotient Inventory, a 133-item questionnaire to evaluate the total El scores of the students by measuring intrapersonal, interpersonal, stress management, adaptability and general mood with a 5-point Likert scale (almost always $=5$, usually $=4$, often $=3$, rarely $=2$, almost never $=1$ ) [23]. The Farsi version of this questionnaire was validated in the Iranian population by Dehshiri [24] and mean reliability of it was reported to be 0.73 . Cronbach's $\alpha$ for this questionnaire in the present study was 0.93 .

\section{Outcome variables}

The dependent variable was the self-reported lifetime use of illicit drugs. The outcome was assessed using the following question: "Until now, have you ever tried drugs, such as marijuana, opium, heroin, amphetamines, ecstasy, or other illegal substances?" [25]. A similar item has been used in previous research on lifetime drug use of adolescents in Iran [12, 13].

The type of illicit substances and the frequency of use were not asked because of prohibiting regulations of the Ministry of Education in the Islamic Republic of Iran. As a result, substance use in the previous month/year or on a regular basis were not considered.

\section{Statistical analysis}

We first used the $\chi^{2}$ test and $t$-test to analyse the relations between demographic characteristics such as having religious beliefs and school performance as well as variables reflecting parents or peer effect, self-esteem, attachment and EI scores and the dependent variable: lifetime selfreported substance use by adolescents. These analyses were done separately in boys and girls to determine the differences between genders. In the next step, the mentioned variables were entered into logistic regression analyses to predict the substance use separately in boy and girl adolescents. The missing data were relatively few. The data were analysed by using the SPSS statistical package and a $p$ value less than 0.05 was considered significant.

\section{Code of ethics}

Before starting the study, all participants were given information about the purpose of the study. Verbal consent' names were not recorded to assure confidentiality. All participants were informed that they could withdraw consent at any time during the interview, by either choosing not to participate or by leaving it. We believe that we have conducted this study according to the 'Ethical Principles for Medical Research involving Human Subjects' of the Helsinki Declaration [26].

\section{Results}

\section{Total participants}

The mean age of boys and girls was $16.1 \pm 1.0$ and $15.9 \pm 1.0$, respectively. The age distribution and their grades in high school are summarized for the two genders separately in Table I. 
From the total of 573 boys, 58 students (10.1\%) reported a history of illicit substance use. This proportion was 35 out of 548 (6.4\%) for girls. The

Table I. Age distribution and school grades of boys and girls

\begin{tabular}{|lcc|}
\hline & $\begin{array}{c}\text { Boys }(N=573) \\
n(\%)\end{array}$ & $\begin{array}{c}\text { Girls }(N=551) \\
n(\%)\end{array}$ \\
\hline Age & $18(3.1 \%)$ & $39(7.1 \%)$ \\
\hline 14 years old or less & $155(27.1 \%)$ & $170(30.9 \%)$ \\
\hline 15 years old & $194(33.9 \%)$ & $199(36.1 \%)$ \\
\hline 16 years old & $156(27.2 \%)$ & $116(21.1 \%)$ \\
\hline 17 years old & $50(8.7 \%)$ & $27(4.9 \%)$ \\
\hline 18 years old & $76(13.3 \%)$ & $350(63.5 \%)$ \\
\hline Grade in High School & $217(37.9 \%)$ & $128(23.2 \%)$ \\
\hline First grade & $280(48.9 \%)$ & $73(13.2 \%)$ \\
\hline Second grade & & \\
\hline Third grade & $275(47.9 \%)$ & $270(49.0 \%)$ \\
\hline Family income level & $298(52.1 \%)$ & $281(51.0 \%)$ \\
\hline More than 400 US $\$$ & & \\
\hline 400 US \$ or less & $17(3.0 \%)$ & $8(1.5 \%)$ \\
\hline Religion & & \\
\hline Muslim & & \\
\hline Others & & \\
\hline
\end{tabular}

difference between the genders regarding the selfreported history of illicit substance use was statistically significant ( $p$-value $=0.023$ ).

\section{Gender differences in predictors of lifetime illicit drug use}

In the regression analyses conducted separately in boys and girls, some predictors of self-reported history of substance use remained in the model, for boys, but not girls. These included history of substance use in the family $(R R=11.0)$, attachment $(R R=1.023)$, and employment of mother $(R R=$ 0.299). These variables did not remain in the regression model in girls (Table III).

\section{Discussion}

In a representative sample of high schools in Tehran, Iran, in 2007, gender affects not only the lifetime prevalence of drug use, but also its psychosocial predictors. Boys were more likely to report lifetime drug use than girls, and three familyrelated variables, namely having a history of substance use in the family, work of the mother and attachment were risk factors of lifetime drug use only in boys.

Gender difference regarding substance use during adolescence is a controversial subject in the literature. While some researchers provide evidence

Table II. Associating factors with self-reported history of substance use in boys and girls

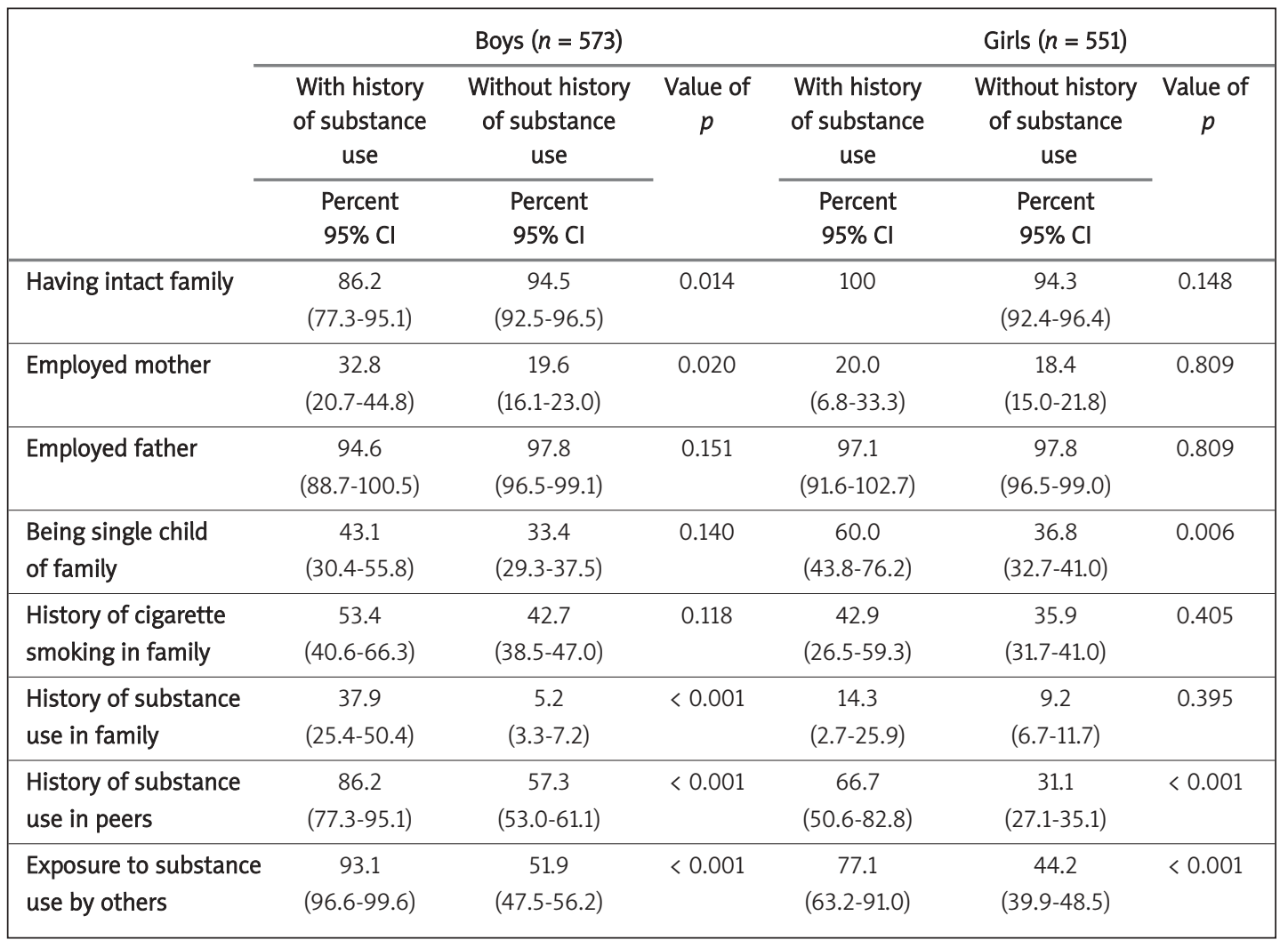


Table III. Associating factors with self-reported history of substance use in boys and girls

\begin{tabular}{|c|c|c|c|c|c|c|}
\hline & \multicolumn{3}{|c|}{ Boys } & \multicolumn{3}{|c|}{ Girls } \\
\hline & $\begin{array}{c}\text { With history } \\
\text { of substance } \\
\text { use }\end{array}$ & $\begin{array}{c}\text { Without history } \\
\text { of substance } \\
\text { use }\end{array}$ & $\begin{array}{c}\text { Value of } \\
p\end{array}$ & $\begin{array}{l}\text { With history } \\
\text { of substance } \\
\text { use }\end{array}$ & $\begin{array}{c}\text { Without history } \\
\text { of substance } \\
\text { use }\end{array}$ & $\begin{array}{c}\text { Value of } \\
p\end{array}$ \\
\hline & $\begin{array}{c}\text { Mean } \\
(95 \% \mathrm{Cl})\end{array}$ & $\begin{array}{c}\text { Mean } \\
(95 \% \mathrm{Cl})\end{array}$ & & $\begin{array}{c}\text { Mean } \\
(95 \% \mathrm{Cl})\end{array}$ & $\begin{array}{c}\text { Mean } \\
(95 \% \mathrm{Cl})\end{array}$ & \\
\hline School performance & $\begin{array}{c}7.2 \\
(6.7-7.6)\end{array}$ & $\begin{array}{c}8.9 \\
(8.8-9.1)\end{array}$ & $<0.001^{* *}$ & $\begin{array}{c}7.4 \\
(6.9-7.9)\end{array}$ & $\begin{array}{c}9.6 \\
(9.5-9.8)\end{array}$ & $<0.001^{\star *}$ \\
\hline Religious beliefs & $\begin{array}{c}15.0 \\
(14.1-15.9)\end{array}$ & $\begin{array}{c}16.9 \\
(16.7-17.1)\end{array}$ & $<0.001^{\star \star}$ & $\begin{array}{c}14.5 \\
(13.7-15.3)\end{array}$ & $\begin{array}{c}16.6 \\
(16.3-16.8)\end{array}$ & $<0.001^{* *}$ \\
\hline $\begin{array}{l}\text { Total score } \\
\text { of self-esteem }\end{array}$ & $\begin{array}{c}28.8 \\
(26.4-31.1)\end{array}$ & $\begin{array}{c}36.9 \\
(36.1-37.6)\end{array}$ & $<0.001^{\star \star}$ & $\begin{array}{c}30.6 \\
(27.2-34.0)\end{array}$ & $\begin{array}{c}37.7 \\
(36.9-38.5)\end{array}$ & $<0.001^{\star \star}$ \\
\hline $\begin{array}{l}\text { Total score } \\
\text { of attachment }\end{array}$ & $\begin{array}{c}229.0 \\
(219.9-238.2)\end{array}$ & $\begin{array}{c}264.5 \\
(261.5-267.4)\end{array}$ & $<0.001^{\star \star}$ & $\begin{array}{c}230.5 \\
(217.3-243.5)\end{array}$ & $\begin{array}{c}269.7 \\
(266.5-272.9)\end{array}$ & $<0.001^{\star *}$ \\
\hline $\begin{array}{l}\text { Total score } \\
\text { of emotional } \\
\text { intelligence }\end{array}$ & $\begin{array}{c}403.0 \\
(388.6-417.5)\end{array}$ & $\begin{array}{c}466.9 \\
(462.2-471.5)\end{array}$ & $<0.001^{\star *}$ & $\begin{array}{c}404.4 \\
(380.5-428.3)\end{array}$ & $\begin{array}{c}458.1 \\
(453.7-462.7)\end{array}$ & $<0.001^{* *}$ \\
\hline
\end{tabular}

${ }^{*} p$ value $<0.05$ by $\chi^{2}$ test, ${ }^{* *} p$ value $<0.05$ by $\mathrm{t}$-test

of a difference between genders regarding time of initiation, type of substance and other characteristics of substance use [27, 28], some others believe that this difference is mostly influenced by culture and background [29].

Most of the studies focusing on gender differences in drug use have named gender as an important predictor of substance use [6, 7, 27, 30], and this effect may be explained by many psychological, cognitive and behavioural differences between males and females [8]. The predictive effect of gender for substance use is explained by dissimilar reasons of boys and girls to initiate and continue substance use [7]. In total, substance use is sex-related (puberty), gender-specific (environmental tobacco smoking, alcohol consumption, drug abuse) and is affected by sex/gender (regular sexual intercourse) [31].

Drug control policy makers in most countries hope for a lower prevalence of drug use in females in their served society. However, they are aware of the global growing pattern of a substance use epidemic in females [28]. In a few countries, with no significant gender difference in lifetime illicit

Table IV. Gender-sensitive predictive factors for substance use in adolescents

\begin{tabular}{|lcccccc|}
\hline & \multicolumn{7}{c}{ Boys } & \multicolumn{3}{c|}{ Girls } \\
\cline { 2 - 7 } & $\mathrm{RR}$ & $\mathrm{Cl}(95 \%)$ & Value of $p$ & $\mathrm{RR}$ & $\mathrm{Cl}(95 \%)$ & Value of $p$ \\
\hline $\begin{array}{l}\text { Exposure to substance } \\
\text { use by others }\end{array}$ & 3.461 & $1.091-10.979$ & 0.035 & 4.354 & $1.360-13.942$ & 0.013 \\
\hline $\begin{array}{l}\text { History of substance } \\
\text { use in peers }\end{array}$ & 5.021 & $1.559-16.172$ & 0.007 & 4.095 & $1.433-11.705$ & 0.009 \\
\hline $\begin{array}{l}\text { Poorer school } \\
\text { performance }\end{array}$ & 1.391 & $1.105-1.753$ & 0.005 & 2.000 & $1.424-2.808$ & $<0.001$ \\
\hline $\begin{array}{l}\text { Lower score of } \\
\text { emotional intelligence }\end{array}$ & 1.014 & $1.007-1.021$ & $<0.001$ & 1.023 & $1.012-1.034$ & $<0.001$ \\
\hline $\begin{array}{l}\text { Family history } \\
\text { of substance use }\end{array}$ & 11.000 & $3.605-33.566$ & $<0.001$ & - & - & - \\
\hline Employed mother & 1.299 & $1.115-1.776$ & 0.013 & - & - & - \\
\hline $\begin{array}{l}\text { Lower score } \\
\text { of attachment }\end{array}$ & 1.023 & $1.008-1.038$ & 0.002 & - & - & - \\
\hline
\end{tabular}


drug use [32], the lack of gender differences has warned of the rapidly increasing drug availability for women [33].

In both genders, better school performance was associated with substance use. Although most studies report a link between academic problems such as school dropout or absenteeism [34], we explain our findings with the effect of "study drugs" which enhance academic performance [35]. Some students use stimulants, such as Ritalin or amphetamines, to improve concentration, increase alertness, and obtain a high mood. A proportion of students used drugs "to study" [36].

We have found that the effect of family (positive family history of substance use and work of the mother and attachment) was a predictor of lifetime drug use in boys only and not girls. One study showed that the most influential familial interaction factor in this regard is the time spent with family [37].

An employed mother was also a risk factor of drug involvement in boys, not girls. According to one study, among parental factors, the employment status of the parents was shown to play a significant role in substance use of neither boys nor girls [38]. However, parental factors have a predictive effect of substance use in adolescents [27]. A close relationship with parents is believed to be a protective factor. Substance use may be more frequent among adolescents who are more disengaged from traditional social cultures (such as family) and look for links outside the family such as peer groups [27]. However, most studies show that this effect is present in both boys and girls in a similar pattern $[4,39]$. There is strong evidence that an intact family is a crucial factor in substance use of adolescents.

Some studies show that an intact family is a predictor for substance use neither in girls nor boys [27]. On the other hand, some others show this effect in girls [40,41]. The relationship between child and parents is an important component of the parental factor in substance use by adolescents. Closeness of parents to their children reduces the risk of substance use in adolescents $[42,43]$. This fact is present even when the parents are divorced but each of them continues their close relationship and shows enough attention and love to their children [9].

Based on the results of the current study, a history of substance use in the family was only a risk factor for drug use in boys and not girls. According to the literature, illicit drug use in parents is highly associated with substance use in adolescents [2, 41]. But in contrast to our study, one study reported this link to be more important in girls [44].

Attachment to father, mother and friends is also an important predictor of substance use in adolescents. A good attachment between child and parents leads them to have a good mutually affectionate, conflict-free relationship that can support adolescents to be well-adjusted individuals who do not use substances [2]. In this study, we considered the effects of parents and peers as their history of cigarette and substance use as well as work of each parent separately in boys and girls.

Also, attachment was a predictor of substance use among boys but not girls. These results show the prominent importance of the effect of family characteristics on the behaviour of boys, rather than that of girls. One study reports parental supervision to be more important in relation to males' than females' history of drug use [45].

The gender differences in predictors of drug use in adolescents show that gender is a key factor in approaching drug prevention in male and female adolescents. This will generate important new insights into how drug use is initiated in boys and girls. This information can be used to design selective preventive strategies [46], which are recommended for decreasing the high community burden of drug use [47], especially for countries with limited resources. Such substance abuse prevention programmes are regularly implemented in some countries worldwide, and they have shown promising results [48-50]. Such gender-specific interventions for drug use prevention have been suggested elsewhere as well [51]. Unfortunately, currently, strategies of drug prevention in Iran are not evidence based.

These gender differences in substance consumption should be taken into account in the development of preventive and treatment strategies for undergraduate university students [52]. Sex differences have been observed in the development of drug addiction and relapse to drug taking [53]. Compared to male subjects, female subjects were younger, were less educated, had higher rates of unemployment and had earlier onset of illicit drug use. Female subjects were 11-fold more likely than male subjects to exhibit suicidal behaviour. Among heroin abusers in the present study, female subjects were more widely exposed to unfavourable social factors and had a substantially higher incidence of suicidal behaviour than male subjects. Drug treatment centres should be aware of the gender differences and pay particular attention to different patterns of drug use and its outcomes among male and female drug abusers [54]. Some studies report poorer outcome for males [55] and some others for females [54]. Males and females may have different experience of relapse in substance use treatment [56] and behavioural changes due to drugs [57].

Analysis revealed that women are significantly more likely than men to use any prescribed drug, and that this gender difference is primarily driven 
by women's increased risk for narcotic analgesic and minor tranquilizer non-medical use. Other factors, such as race, age, health status, and other substance use, are also significant predictors of non-medical use. Findings from this study will enable researchers as well as policy makers and providers to have a greater understanding of nonmedical drug use patterns and support greater gender sensitivity in the prevention, education, and treatment of non-medical prescription drug use [58].

Similarly to other studies, the present study has some limitations, such as measurement bias [27] and relying on self-reported drug use (which is reported as valid among teenagers) [59]. The crosssectional design of most of these studies does not allow aetiological inferences. However, we should keep in mind that it is better not to consider only adolescents in school, although some other studies did the same [31, 32]. With this method, we should be careful about the interpretation of the results of the present study. Positive points in our study may include high response rate, equal sample size in genders and considering a wide range of associating factors of substance use in adolescents at the same time. It should be mentioned that although there are large databases in western developed countries on substance use in adolescents, there is a lack of data in low and middle income countries. In contrast to developed countries with known predictors for adolescent substance use, much remains to understand about predictors in developing countries [2].

In conclusion, the prevalence of lifetime drug use is higher in male than female high school adolescents in Tehran, Iran. In addition, the gender difference in psychosocial associated factors necessitates gender-sensitive drug control policies to be designed for illicit drug use prevention. According to the current results, family data may be more important in prevention of drug use in boys than in girls.

\section{References}

1. Sullivan MD, Edlund MJ, Zhang L, Unützer J, Wells KB. Association between mental health disorders, problem drug use, and regular prescription opioid use. Arch Intern Med 2006; 166: 2087-93.

2. Brook JS, Morojele NK, Paul K, Brook DW. Predictors of drug use among South African adolescents. J Adolesc Health 2006; 38: 26-34.

3. Toumbourou JW, Hemphill SA, Tresidder J, Humphreys C, Edwards J, Murray D. Mental health promotion and socioeconomic disadvantage: lessons from substance abuse, violence and crime prevention and child health. Health Promot J Austr 2007; 18: 184-90.

4. Kokkevi AE, Arapaki AA, Richardson C, Florescu S, Kuzman M, Stergar E. Further investigation of psychological and environmental correlates of substance use in adolescence in six European countries. Drug Alcohol Depend 2007; 88: 308-12.

5. Riley $\mathrm{H}$, Schutte NS. Low emotional intelligence as a predictor of substance-use problems. J Drug Educ 2003; 33: 391-8.

6. Chen KT, Chen CJ, Fagot-Campagna A, Narayan KM. Tobacco, betel quid, alcohol and illicit drug use among 13- to 35-year-olds in I-Lan, Rural Taiwan: prevalence and risk factors. Am J Public Health 2001; 91: 1130-33.

7. Isralowitz R, Rawson R. Gender differences in prevalence of drug use among high risk adolescents in Israel. Addict Behav 2006; 1: 355-8.

8. Hass K. Relationship of gender to licit and illicit drug use among adolescents. chrestomathy. Annual Review of Undergraduate Research at the College of Charleston 2004; 3: 92-100.

9. Ledoux S, Miller P, Choquet M, Plant M. Family structure, parent-child relationships, and alcohol and other drug use among teenagers in France and the United Kingdom. Alcohol 2002; 37: 52-60.

10. Fitzgerald R. An examination of sex differences in delinquency. Crime and Justice Research Paper Series; Catalogue no. 85-561-MIE2003001: 2003.

11. Freidman AS, Granick S, Bransfield S, Kreishe C, Khalsa J. Gender differences in early life risk factors for substance use/ abuse: a study of an African-American sample. Am J Drug Alcohol Abuse 1995; 21: 511-31.

12. Ahmadi J, Hasani M. Prevalence of substance use among Iranian high school students. Addict Behav 2003; 28: 375-9.

13. Mohammad Poorasl A, Vahidi R, Fakhari A, Rostami F, Dastghiri S. Substance abuse in Iranian high school students. Addict Behav 2007; 32: 622-7.

14. Mohammadpoorasl A, Fakhari A, Rostami F, Vahidi R. Predicting the initiation of substance abuse in Iranian adolescents. Addict Behav 2007; 32: 3153-9.

15. Agahi C, Spencer C. Beliefs and opinions about drugs and their users as predictors of drug-user status of adolescents in post-revolutionary Iran. Drug Alcohol Depend 1982; 10: 99-110.

16. Shadnia S, Esmaily H, Sasanian G, Pajoumand A, Hassanian-Moghaddam H, Abdollahi M. Pattern of acute poisoning in Tehran-Iran in 2003. Hum Exp Toxicol 2007; 26: 753-6.

17. Moghadamnia AA, Abdollahi M. An epidemiological study of acute poisonings in northern Islamic Republic of Iran. East Medit Health J 2002; 8: 88-94.

18. Collins NL, Read SJ. Adult attachment, working models, and relationship quality in dating couples. J Personal Social Psychol 1990; 58: 644-63.

19. Pakdaman, et al. Psychometric properties of Farsi translation of inventory of Collins \& Read's Adult attachment. 2006. Not published.

20. Coopersmith S. Coopersmith inventory manual. Palo Alto, CA: Consulting Psychologists Press 1981.

21. Hosseini MA, Dejkam M, Mirlashari J. Correlation between Academic Achievement and Self-esteem in Rehabilitation Students in Tehran University of Social Welfare \& Rehabilitation. Ir J Med Educ 2007; 7.

22. Asadi I, Azar S, Vasudeva P. Self-efficacy and self-esteem: a comparative Study of employed and unemployed married women in Iran. G J Psych 2005; 9: 111-7.

23. Bar-On R. The Bar-On model of emotional - social intelligence (ESI). Psicothema 2006; 18: 13-25.

24. Dehshiri GR. Relationship between emotional intelligence and student academic achievement. Counsel Res Develop 2006; 5: 97-106. 
25. Global School-based Student Health Survey. Thailand GSHS Questionnaire 2008. Available at: http://www.who. int/chp/gshs/2008_Thailand_GSHS_questionnaire.pdf.

26. The World Medical Association: World Medical Association Declaration of Helsinki: Ethical principles of research involving human subjects. Available at: [http://www.wma. net/e/policy/b3.htm].

27. Ljubotina D, Galić J, Jukić V. Prevalence and risk factors of substance use among urban adolescents: questionnaire study. Croat Med J 2004; 45: 88-98.

28. Litt IF. Drugs and adolescent girls. J Adolesc Health 2003; 32: 1-2.

29. Rodriguez J, Hernandez E, Fernandez AM. A gender comparison of legal and illicit drug consumption. Rev Med Chil 2007; 135: 449-56.

30. Isralowitz R, Reznik A. Gender differences among Israeli adolescents in residential drug treatment. Drugs Educ Prev Pol 2007; 14: 167-72.

31. Kalaboka S, Piau JP, King G, Moreau D, Choquet M, AnnesiMaesano I. Sex and gender differences in tobacco smoking among adolescents in French secondary schools. Monaldi Arch Chest Dis 2008; 69: 142-51.

32. Gunnarsson M, Fahlke C, Balldin J. Adolescents who have tried illicit drugs and experienced psychiatric symptoms seldom seek professional help. A pilot study of 18-year old high school students in an urban district. Lakartidningen 2004; 101: 1280-2.

33. Diala CC, Muntaner C, Walrath C. Gender, occupational, and socioeconomic correlates of alcohol and drug abuse among U.S. rural, metropolitan, and urban residents. Am J Drug Alcohol Abuse 2004; 30: 409-28.

34. Tavares BF, Béria JU, Silva de Lima M. Drug use prevalence and school performance among adolescents. Rev Saude Publica 2001; 35: 150-8.

35. Sussman S, Pentz MA, Spruijt-Metz D, Miller T. Misuse of "study drugs:" prevalence, consequences, and implications for policy. Subst Abuse Treat Prev Policy 2006; 1: 15.

36. Teter CJ, McCabe SE, Cranford JA, Boyd CJ, Guthrie SK. Prevalence and motivations for the illicit use of prescription stimulants in an undergraduate student sample. J Am Coll Health 2005; 53: 253-62.

37. Adlaf EM, Ivis FJ. The influence of familial factors on adolescent substance use and delinquency. J Child Adolesc Subst Abuse 1996; 5: 1-19.

38. Hillman SB, Sawilowsky SS. Maternal employment and early adolescent substance use. Adolescence 1991; 104: 829-37.

39. Urberg KA, Değirmencioğlu SM, Pilgrim C. Close friend and group influence on adolescent cigarette smoking and alcohol use. Dev Psychol 1997; 33: 834-44.

40. Plant MA, Plant ML. Risk-takers: alcohol, drugs, sex, and youth. Tavistock Routledge, New York Page Number: iii. 1992.

41. Denton RE, Kampfe CM. The relationship between family variables and adolescent substance ab use: a literature review. Adolescence 1994; 29: 475-95.

42. Kandel DB, Kessler RC, Margulies RZ. Antecedents of adolescent initiation into stages of drug use: a developmental analysis. J Youth Adolescence 1978; 7 : 13-40.

43. Kandel DB, Andrews K. Processes of adolescent socialization by parents and peers. Subst Use Misuse 1987; 22: 319-42.

44. Silveri MM, Tzilos GK, Pimentel PJ, Yurgelun-Todd DA. Trajectories of adolescent emotional and cognitive development: effects of sex and risk for drug use. Ann N Y Acad Sci 2004; 1021: 363-70.
45. McArdle P, Wiegersma A, Gilvarry E, et al. European adolescent substance use: the roles of family structure, function and gender. 2007; 97: 329-36.

46. SAMHSA. Clinical Preventive Services in Substance Abuse and Mental Health Update: From Science to Services 2008.

47. UNDCP. Investing in Drug Abuse Treatment-A Discussion Paper For Policy Makers. The United Nations International Drug Control Programme 2003.

48. Botvin GJ, Griffin KW. School-based programmes to prevent alcohol, tobacco and other drug use. Int Rev Schiatry 2007; 19: 607-15

49. Seal N. Preventing tobacco and drug use among Thai high school students through life skills training. Nurs Health Sci 2006; 8: 164-8.

50. Griffin KW, Botvin GJ, Nichols TR. Long-term follow-up effects of a school-based drug abuse prevention program on adolescent risky driving. Prevent Sci 2004; 5: 207-12.

51. Schinke S, Schwinn T. Gender-specific computer-based intervention for preventing drug abuse among girls. Am J Drug Alcohol Abuse 2005; 31: 609-16.

52. Wagner GA, Stempliuk Vde A, Zilberman ML, Barroso LP Andrade AG. Alcohol and drug use among university students: gender differences. Rev Bras Psiquiatr 2007; 29: 123-9.

53. Yu J, Zhang S, Epstein DH, et al. Gender and stimulus difference in cue-induced responses in abstinent heroin users. Pharmacol Biochem Behav 2007; 86: 485-92.

54. Chiang SC, Chan HY, Chang Y, Sun HJ, Chen WJ, Chen CK Psychiatric comorbidity and gender difference among treatment-seeking heroin abusers in Taiwan. Psychiatry Clin Neurosci 2007; 61: 105-11.

55. Antolini G, Pirani M, Morandi G, Sorio C. Gender difference and mortality in a cohort of heroin users in the Provinces of Modena and Ferrara, 1975-1999. Epidemiol Prev 2006; 30: 91-9.

56. Walitzer KS, Dearing RL. Gender differences in alcohol and substance use relapse. Clin Psychol Rev 2006; 26: 128-48.

57. Fillmore MT, Weafer J. Alcohol impairment of behavior in men and women. Addiction 2004; 99: 1237-46.

58. Simoni-Wastila L, Ritter G, Strickler G. Gender and other factors associated with the nonmedical use of abusable prescription drugs. Subst Use Misuse 2004; 39: 1-23.

59. Carroll KM. Methodological issues and problems in the assessment of substance use. Psychol Assess 1995; 7 : 349-58. 